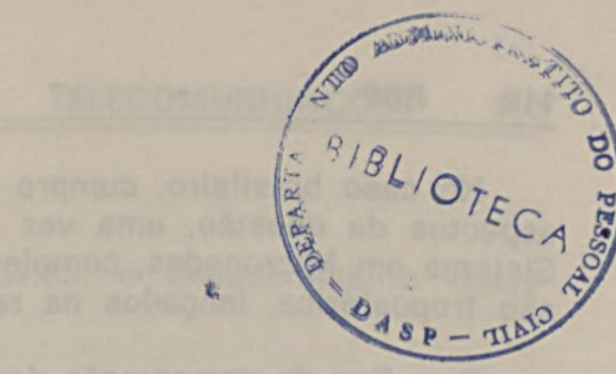

\title{
Telecomunicações por Satélite
}

\begin{abstract}
George M. Ney da Silva
Engenheiro de Telecomunicações; ex-Diretor da Divisăo de Engenharia do Departamento Nacional de Telecomunicações; selecionado pela União Internacional de Telecomunicaçōes (UIT), com sede em Genebra, Sufça, exerceu (1970-72) o cargo de Engenheiro-adjunto do "International Frequence Board" (IFRB).
\end{abstract}

SUMARIO - Diante de um problema da mais alta relevância encontra-se o Ministério das Comunicações: a tomada de posição quanto à implantação no Brasil de um Sistema de Telecomunicações por Satélite Doméstico. $\mathrm{Na}$ imprensa diária e em revistas especializadas estampam-se artigos onde grupos divergentes buscam ressaltar as vantagens das técnicas que defendem. Urge, entretanto, uma análise global que compare as duas soluções em causa, quais sejam: - Sistema Espacial (por Satélites) e - Sistema Terrestre (microondas em visibilidade). Neste artigo visa-se esboçar tal análise. Nele se expōe ponto de vista pessoal e, para tanto, o autor se fundamenta na documentação de que dispõe.

\section{1 - INTRODUÇÃO}

É o Brasil um país em desenvolvimento e de grande extensão territorial. Suas concentrações populacionais surgiram em decorrência de desenvolvimentos regionais e setoriais, criando assim os polos econômicos existentes. Como possíveis soluções para as necessidades em telecomunicações, costuma-se alinhar a utilização de uma ou mais das seguintes técnicas de enlaces radioelétricos:

- propagação ionosférica;

- microondas (em visibilidade);

- difusão troposférica (trans-horizonte); e

- satélite. 
No caso brasileiro, cumpre analisar, no momento, outros aspectos da questão, uma vez que o país já dispõe de um Sistema em Microondas, complementado por enlaces em difusão troposférica, lançados na região amazônica.

Para fins de comparação dos dois sistemas, foi escolhida, como Modelo de Necessidades a atender, a ligação entre grandes centros das regiões Centro-Oeste, Nordeste, Leste e Sul (já atendidos pelo Sistema da Embratel) a pequenos centros (não atendidos). Nestes últimos, incluem-se os existentes, e os em desenvolvimeno, bem como os previstos no Plano de Integração da Amazônia. Foram julgados necessários, para atender ao modelo acima e considerando-se a utilização simultânea do Sistema atual da Embratel:

- No Sistema Espacial: 3 satélites, 3 estações terrenas de elevado tráfego, 8 estações terrenas de médio tráfego e 30 estações de baixo tráfego. A capacidade dos satélites foi arbitrada em 5000 canais telefônicos por satélite, para 2 satélites em órbita. $O$ terceiro satélite é mantido disponivel em terra.

- No Sistema Terrestre: $6000 \mathrm{~km}$ de enlaces com capacidade variando de 60 a 1800 canais telefônicos, com lances médios de $30 \mathrm{~km}$.

Os demais títulos do artigo objetivam permitir uma análise do problema atualmente em foco na Administração Federal e examinar aspectos julgados importantes para o equacionamento do mesmo. Assim, em adequada seqüência, desenvolvem-se, aqui, os seguintes títulos:

- CUSTOS

- CONDIÇÕES DE ACESSO

- FLEXIBILIDADE

- CAPACIDADE DE TRAFEgo

- DURABILIDADE

- CONFIABILIDADE

- BENEFICIOS DECORRENTES

- OPORTUNIDADE e

- CONCLUSÃO. 


\section{2 - CUSTOS}

Impõe-se, por motivos óbvios, o desdobramento deste aspecto em dois:

- Custo de transmissão; e

- Custo de instalação.

\section{1 - Custo de Transmissão:}

Sistema Espacial - Suposta a existência de uma rede básica terrestre para concentração e distribuição de tráfego, na região das estações terrenas, os custos para uma transmissão a $600 \mathrm{~km}$ ou a $6000 \mathrm{~km}$ serão praticamente da mesma ordem. 0 custo de transmissão para o conjunto do Sistema pode ser considerado, em média, $40 \%$ inferior ao custo em Microondas.

Sistema Terrestre - 0 custo de transmissão aumenta proporcionalmente à quantidade de terminais necessários para cobrir as distâncias dos enlaces. $\mathrm{O}$ aumento de terminais implica maior número de operadores e um reforço nas equipes fixas e móveis de manutenção, onerando assim o custo operacional do sistema.

\section{2 - Custo de instalação:}

Sistema Espacial - Tomando como base as necessidades indicadas anteriormente e o aproveitamento do atual Sistema da Embratel, obtém-se, como custo estimativo, o valor de 550 milhões de cruzeiros.

Sistema Terrestre - Neste caso o Sistema da Embratel deVeria ser complementado por mais $6000 \mathrm{~km}$ de enlaces, o que pode ser estimado em 150 milhões de cruzeiros, aceito o lance médio de $30 \mathrm{~km}$ como viável, na região amazônica.

\section{3}

\section{- CONDIÇÕES DE ACESSO}

diata-se aqui de medir a possibilidade de atendimento imediato e direto, sem necessidade de retransmissões, por parte dos terminais de cada sistema.

Sistema Espacial - É um sistema que oferece boas condifões de acesso, pois onde quer que se deseje poderá ser instalado um terminal com acesso direto ao satélite. 
Sistema Terrestre - O acesso ao Sistema Básico é obtido, algumas vezes, por repetições de sinal. $O$ atendimento se faz ao longo de rotas predeterminadas, o que, no caso da região amazônica, até então representava grande obstáculo. Com a execução da Transamazônica e suas transversais, têm-se agora melhores condições de levar o sinal através da selva, na direção dos núcleos populacionais que margearão as estradas. № cômputo geral, o acesso neste Sistema pode ser considerado da ordem de $80 \%$ em relação ao Espacial.

\section{4 - FLEXIBILIDADE}

É a capacidade de um sistema em atender, com a presteza necessária, à diversificação normal e esporádica na demanda de tráfego do sistema, seja por exagerada solicitação no próprio centro de comutação, como pela ocorrência de fatos geradores de novas ou maiores zonas de tráfego, temporárias ou permanentes (emergências, segurança, calamidade, etc.).

\section{1 - Sistema Espacial}

Quanto à utilização de equipamentos transportáveis em terra, ambos sistemas se equivalem. Quanto à presteza do centro comutador, o satélite, sem dúvida, leva vantagem, uma vez que este comuta diretamente quaisquer terminais entre $\mathrm{si}$, por $\cdot \mathrm{co}^{-}$ mando da Central de Controle de Tráfego, em terra.

\section{2 - Sistema Terrestre}

Sua flexibilidade é limitada ao raio de ação das rotas $e$ sub-rotas, dimensionadas com base em necessidades presumíveis para o futuro. Pode ser estimada em $85 \%$ daquela obtida com satélites.

\section{5 - CAPACIDADE DE TRAFEGO}

A capacidade de tráfego é dada pela possibilidade que oferece o Sistema de atender a uma maior ou menor quantidade de canais simultaneamente.

\section{1 - Sistema Espacial}

Analisando-se um enlace isolado, esta solução apresenta vantagem extraordinária, pois o sistema pode, a qualquer momento, aplicar toda sua capacidade ( 10000 canais telefônicos) 
entre dois pontos quaisquer. A medida que o número de enlaces aumenta, a capacidade de tráfego por enlace diminui proporcionalmente, a menos que novas técnicas, recentemente desenvolvidas, venham a ser empregadas na comutação por satélite. Levantamentos realizados na Embratel indicam que, em 1975, algumas cidades brasileiras apresentarão as seguintes necessidades de tráfego interurbano:

$\begin{array}{lr}\text { Porto Alegre } & 1000 \text { canais telefônicos } \\ \text { São Paulo } & 5000 \text { canais telefônicos } \\ \text { Belém } & 800 \text { canais telefônicos }\end{array}$

Se tomarmos como exemplo um satélite com capacidade de 7000 canais, ele já estaria com suas possibilidades praticamente esgotadas.

Este mesmo satélite não teria condições de atender, em 1975, ao tráfego exigido por 10 cidades com porte de tráfego idêntico ao de Belém. O satélite satisfaz prontamente, numa emergência, à demanda não prevista, cujo atendimento por microondas estaria sujeito a um longo retardo.

\section{2 - Sistema Terrestre}

Neste sistema, suas rotas são dimensionadas de modo que possa suportar o tráfego previsto em estudos da demanda em telecomunicações, nas regiões a serem atendidas. Evidenciase, assim, a superioridade das Microondas, neste aspecto, para sistemas em operação normal. Esta solução é a melhor por se tratar, digamos assim, de um sistema "sob medida", em todas as ramificações. O Sistema Espacial poderia oferecer também uma solução "sob medida", mas redundaria em aumento no Custo de instalação.

\section{6 - DURABILIDADE}

Este é um aspecto da mais alta importância, em decorrênCia dos seguintes fatores, que normalmente pesam no dimensionamento de sistemas:

- vulto dos empreendimentos;

- continuidade do serviço;

- atualidade, experimentação e afirmação da tecnologia adotada. 


\section{1 - Sistema Espacial}

No estado atual da técnica, a vida útil prevista de um satélite está em torno de 7 (sete) anos, portanto, o vulto dos empreendimentos é grande comparado com o pequeno prazo de garantia de continuidade do serviço. É uma tecnologia que começou a afirmar-se no campo das telecomunicações. O Canadá resolveu explorar seu próprio Sistema de Telecomunicações por Satélite, lançando-o em novembro de 1972, 3 anos e meio após a criação da TELESAT CANADA, por ato do Parlamento Canadense. TELESAT é a companhia proprietária e exploradora do Sistema de Comunicações por Satélite Doméstico do Canadá. Além disso merece citação o fato de que no mundo de hoje $2 / 3$ das comunicações internacionais se fazem por satélites.

\section{2 - Sistema Terrestre}

A experiência desta tecnologia já foi comprovada, quer no âmbito internacional, como no nacional. Levando-se em conta que um sistema de microondas tem uma vida útil estimada em pelo menos 15 anos, o vulto relativo dos empreendimentos, em vista da vida útil mais prolongada, é reduzido.

\section{7 - CONFIABILIDADE}

E a probabilidade que oferece um Sistema à ocorrência de sucessos nas tentativas de ligação entre terminais do referido Sistema. Foram alinhados, por estarem indiretamente correlacionados, ao lado da confiabilidade, dois fatores importantes:

- riscos; e

- segurança.

\section{1 - Sistema Espacial}

A confiabilidade dos enlaces Terra-Satélite-Terra é superior em termos de propagação, pois o meio é praticamente isento do ruído atmosférico, uma vez que o satélite é colocado numa órbita geoestacionária a uma altura aproximada de $36000 \mathrm{~km}$.

Há, porém, além dos riscos normais de suas estações em terra, os riscos decorrentes de possíveis fracassos no lançamento, falhas no comando e rastreio do satélite, bem como demais sensível à possibilidade de falhas. 
Enquanto nossa mão-de-obra especializada não tiver adquirido o "know how" necessário ao lançamento de outros satélites e à operação do sistema, a segurança de funcionamento do mesmo estará, de certa forma, comprometida, por depender de instalação, mão-de-obra e recursos tecnológicos estrangeiros.

Do ponto de vista da confiabilidade dos equipamentos, os sistemas se equivalem.

\section{2 - Sistema Terrestre}

Tendo em vista a superioridade numérica em estações, os riscos em terra e a segurança física inferiorizam esta solução. Por outro lado não entram em linha de consideração falhas ou defeitos de impossivel ou difícil reparação, as quais normalmente são de baixo custo em relação ao sistema por satélites.

A segurança das comunicações é maior no Sistema Terrestre, pois as possibilidades de interceptação, embora bilateral, se reduzem a uma faixa ao longo das rotas em microondas. $O$ satélite, cobrindo uma vasta região, pode ter suas comunicações Satélite-Terra interceptadas em qualquer ponto nela incluído. Hoje em dia, qualquer pessoa, com pequenos conhecimentos e prática de montagem, pode montar dispositivos capazes de captar os sinais emitidos pelos satélites meteorológicos e fazer reproduzir os mapas regionais das condições meteorológicas. No cômputo geral é válido considerar-se que a confiabilidade do satélite é da ordem de $90 \%$ da conseguida por microondas.

\section{8 - BENEFÍCIOS DECORRENTES}

Ambas soluções têm possibilidade de contribuir substancialmente para o desenvolvimento econômico, social e tecnológico do país. Cumpre, entretanto, examinar nossas condições atuais de desenvolvimento naquelas áreas, de forma que não venham a ser prejudicadas por diversificação excessiva. alinhados:

Os benefícios comuns às duas soluções podem ser assim

- integração das regiões isoladas;

- fixação do homem à região; 
- motivação à transferência de mão-de-obra especializada e de equipes gerenciais às regiões até então desprezadas; e

- interiorização da educação, da cultura, da técnica e da informação.

\section{1 - Sistema Espacial}

No campo industrial e tecnológico em geral, é uma solução que, a longo prazo, certamente induzirá no país o desenvolvimento industrial e estrutural capazes de garantir a necessária autonomia operacional do sistema. Possibilitará atendimento rápido às necessidades em telecomunicações nas situações de emergência.

\section{2 - Sistema Terrestre}

Já se tem ponderável noção dos benefícios dessa solução no campo industrial. Hoje em dia, nossa indústria se dedica, com grandes esforços e igual êxito, à produção de equipamentos de microondas para o mercado nacional, gerando assim um mais alto nível de especialização da mão-de-obra e criando mais oportunidades de empregos.

\section{9 - OPORTUNIDADE}

Neste aspecto, analisa-se a conveniência da adoção de uma das soluções, consideradas:

a) a situação atual das telecomunicações no país;

b) os compromissos e a capacidade da indústria nacional em absorver nova tecnologia sem prejudicar o mercado crescente, gerado pela introdução da técnica da microonda no nosso parque industrial eletrônico;

c) a tendência baixista de preços, nos sistemas por satélites e as exigências da regulamentação internacional.

\section{1 - Sistema Espacial}

Depende de um bom sistema em terra que dê prosseguimento ao tráfego entregue pelo satélite a seus terminais. A busca à autonomia operacional (vide 8.1) trará, sem dúvida, diR. Serv. Públ., Brasilia, 108 (2): mai./ago. 1973 
na produção comercial dos equipamentos de microondas necessários não somente ao Sistema da Embratel mas também às Redes Estaduais.

Por outro lado, há necessidade de se garantir o posicionamento de um Satélite Brasileiro, antes que a Coordenação, recomendada pela União Internacional de Telecomunicações (UIT), se torne mais difícil, caso algum país da América do Sul se antecipe ao Brasil.

Estudos recentes indicam a seguinte tendência dos custos e despesas anuais de uma Estação Terrena ( 1.000 canais telefônicos), para sua instalação e operação:

$\begin{array}{llrrrr} & & 1967 & 1970 & 1975 \\ \text { - custo de uma estação } & \text { (US\$ 1.000) } & 6.000 & 3.500 & 2.500 \\ \text { - despesas anuais } & (U S \$ 1.000) & 49 & 38 & 16\end{array}$

Pode-se prever que, entre 1978 e 1980, ocorrerá uma estabilização de custos e despesas, em níveis bem mais econômicos, caso persistam as atuais tendências.

\section{2 - Sistema Terrestre}

A indústria nacional espera que o Governo, caso se decida pela introdução da tecnologia espacial no país, não venha relegar a segundo plano as necessidades do país em equipamentos que se utilizam da técnica de microondas em terra.

Os preços de custo e despesas já se acham estabilizados e 0 índice de nacionalização já é elevado.

\section{0 - CONCLUSÃO}

Antes de apresentar o Quadro Geral de Avaliação, desejo chamar a atenção para a necessidade de se ter em mente que as duas técnicas são não somente compatíveis mas complementares. $O$ desenvolvimento de ambas contribuirá para um melhor atendimento à demanda sempre crescente de meios de telecomunicaçõs mais econômicos e de confiabilidade aceitável. Cabe ao Governo a tarefa de antever e decidir, com base em seus estudos, quando der início à complementação de sistemas. 
A diferença de $21 \%$ no índice de Favorabilidade, se bem que obtido de valores mais subjetivos que matemáticos, reflete a conveniência de se completar primeiro o Sistema de Microondas já iniciado, o qual, servindo de base ao Sistema por Satélites, propiciará a este uma racional utilização de sua capacidade de tráfego, benefícios indiretos e oportunidade de que carece no quadro atual da situação brasileira.

Paralelamente o Brasil deverá empenhar-se em manter em disponibilidade o espaço necessário, na órbita equatorial, para garantir o posicionamento de seu satélite doméstico na época oportuna.

Quanto à Radiodifusão Direta, a partir de Satélites geoestacionários, o Grupo de Trabalho, criado na Comissão de Utilização Pacífica do Espaço Extra-atmosférico da ONU, para estudar os Satélites de Radiodifusão Direta, apresentou, em 1970, um relatório onde estimava que a realização de satélites susceptíveis de retransmitir diretamente ao público programas de televisão só poderia ser possível após 1985, caso se desejasse uma recepção sem qualquer modificação nos atuais receptores individuais. Por outro lado, a recepção direta em receptores e antenas individuais, modificados, poderia tornar-se possivel a partir de 1975, mediante uma elevação desencorajadora do custo do sistema, tanto mais que seria indispensável um considerável aumento na potência dos transmissores a serem colocados em órbita. Contudo o mesmo Grupo fez uma ressalva esclarecendo que a recepção direta de sinais de televisão, mediante o emprego de instalações comunitárias, seria de menor custo e talvez tecnicamente realizável em 1975. Para finalizar, desejo transcrever, a título de informação,
algumas notícias indicativas das tendências atuais das técnicas
em telecomuniscon em telecomunicações:

- O atual Sistema da Embratel abrange $11500 \mathrm{~km}$ de enlaces em microondas e $5100 \mathrm{~km}$ em tropodifusão.

- Os países do Continente Africano, com a orientação do Departamento de Cooperação Técnica da UIT, decidiram partir para a instalação, em 1974, de um Sistema Continental de Comunicações em Microondas, perfazendo
$18000 \mathrm{~km}$ de enlaces. 
- Os Estados Unidos da América (FCC) estudam, atualmente, as propostas apresentadas por grandes grupos para a instalação de um Sistema de Telecomunicações por Satélite Doméstico.

\section{QUADRO GERAL DA AVALIAÇÃO COMPARATIVA ENTRE OS SISTEMAS POR SATÉLITE E DE MICROONDAS}

\section{ASPECTOS CONSIDERADOS}

\begin{tabular}{|c|c|c|c|c|c|c|c|c|c|c|}
\hline & \multicolumn{2}{|c|}{ CUSTOS } & \multirow{2}{*}{$\begin{array}{l}\text { Cond. } \\
\text { Aces- } \\
\text { BO }\end{array}$} & \multirow{2}{*}{$\begin{array}{c}\text { Flexi- } \\
\text { bilida- } \\
\text { de }\end{array}$} & \multirow{2}{*}{$\begin{array}{c}\text { Capa- } \\
\text { cida- } \\
\text { de }\end{array}$} & \multirow{2}{*}{$\begin{array}{c}\text { Dura- } \\
\text { bilida- } \\
\text { de }\end{array}$} & \multirow{2}{*}{$\begin{array}{c}\text { Confia- } \\
\text { bilida- } \\
\text { de }\end{array}$} & \multirow{2}{*}{$\begin{array}{l}\text { Bene- } \\
\text { ficios }\end{array}$} & \multirow{2}{*}{$\begin{array}{l}\text { Opor- } \\
\text { tuni- } \\
\text { dade }\end{array}$} & \multirow{2}{*}{$\begin{array}{l}\text { Ind. } \\
\text { Favora- } \\
\text { bilidade }\end{array}$} \\
\hline & Trans. & Inst. & & & & & & & & \\
\hline Satélite & 10 & 2,7 & 10 & 10 & 5 & 4 & 9 & 7 & 7 & $72 \%$ \\
\hline Microonda & 7 & 10 & 8 & 8,5 & 10 & 10 & 10 & 10 & 10 & $93 \%$ \\
\hline
\end{tabular}

OBS.: Os valores numéricos do presente Quadro foram estabelecidos segundo uma escala variável de 1 a 10, conforme o valor relativo de cada aspecto, quando comparados às possibilidades do outro sistema no mesmo aspecto.

Excetuando-se os referentes a custos, todos os outros são valores subjetivos, baseados nas considerações expostas no texto.

\section{BIBLIOGRAFIA}

- Documentação geral distribuida pelas firmas HUGHES, GE, ITT, FAIRCHILD, TELESAT, INPE, Grupo CIFAS (Consórcio Internacional Francês-Alemão Symphonie) e TRW.

- Telecomunication Journal (Dec. 1968) (July 1969) (Jan, Feb, May 1971) (Jan, Feb 1973).

- Electrical Communications (Vol. 43 n.0 1 1968).

- Astronautics and Aeronautics (Vol. 6 n. ${ }^{\circ} 4$ 1968).

- O Ataque ao Satélite - José Maria Couto de Oliveira - (Jornal OPINIÃO - n.० 16 1973).

- As Comunicaçöes no Brasil - José Maria Nogueira Ramos - (Jornal OPINIÃO — n. ${ }^{\circ} 17$ 1973)

- Engenharia - Revista do Instituto de Engenharia (Nov. 1972). 
.

sis

wank

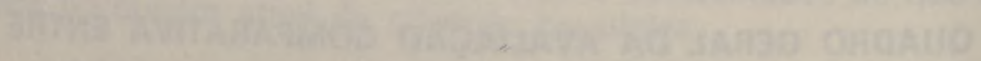

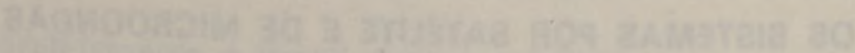

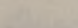

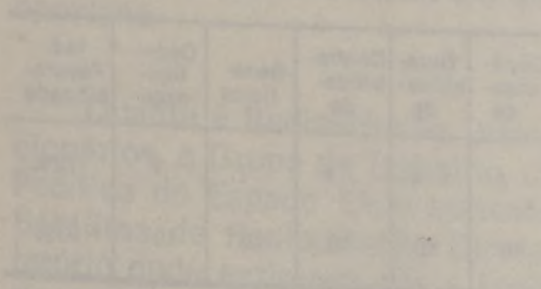

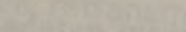

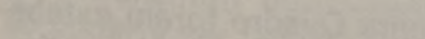

1020

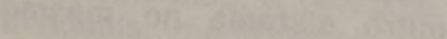

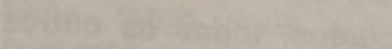

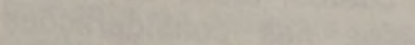

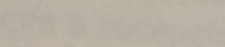

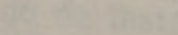

(2)

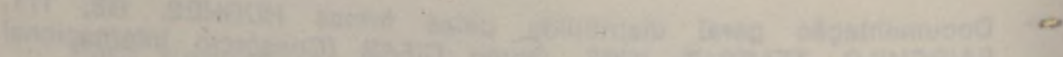

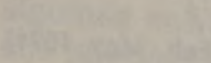

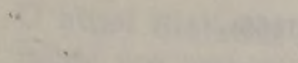

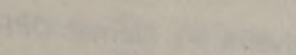

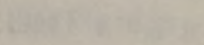

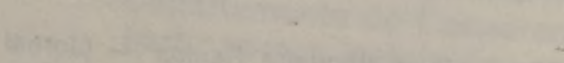

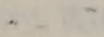

